\title{
VISUALIZING CHEMISTRY - IT-BASED LEARNING IN CHEMISTRY EDUCATION
}

\section{Michael Urbanger \& Andreas Kometz}

Didaktik der Chemie - FAU Erlangen-Nürnberg - Regensburger Str. 160 - 90478 Nürnberg, Germany, michael.urbanger@fau.de, andreas.kometz@fau.de

\begin{abstract}
Learning chemistry is often difficult for students regarding the contents of this natural science. The reason behind this is mostly the degree of abstraction which is necessary to understand the procedures and invisible functional backgrounds of macroscopic processes. Until now this problem has been approached by using pre-built and fixed chemical models and chemical language without subject-specific meaning unknown to the student. To counter this unsatisfying situation it is necessary to find a new way to teach chemistry. In modern society the use of new media like PCs, Tablet-PCs and Smartphones is very common among today's students, and thus it is necessary and absolutely essential to implement those media in modern education. Using these media as a supplement of education is nothing new, but using it as an integrated component in educational training with a whole new form of teaching is a big challenge. The students have to acquire professional (chemical) expertise in combination with media skills as well, not only in chemistry lessons but interdisciplinary with other subjects like Information-Technology or Art. The aim of a project dealing with these needs and requirements is highlighting the inclusion of all aspects of new media in chemistry education and conveyance of skills to depict chemical sub-microscopic processes in conjunction with other subjects of school education. The didactics of chemistry of the Friedrich-Alexander-Universität ErlangenNürnberg is designing an educational programme for students using Tablet-PCs, PCs and art materials which let students literally see chemical processes with self-made models, drawings, $3 \mathrm{D}$-models rendered with CAD-programs, role-playings, blogs for exchanging ideas and data, self-designed virtual and physical experiments, tutorials and presentations.
\end{abstract}

\section{Introduction}

Chemistry is a subject which is, in an average school, quite unpopular with students - and sometimes even among teachers. Students have difficulties in understanding the subject matter itself, especially when it comes to differentiate between the macroscopic, perceptible level and the sub-microscopic, imperceptible level, necessary for explaining chemical coherencies. In addition, the chemical technical language is for most students like a new foreign language, not matching with their everyday language. In particular chemical symbols with multiple meanings are a trigger of misconceptions. For that reason, teachers often have teaching frustration and think the students are "stupid". But they are not - of course -, they just don't have the ability to abstract and visualise the sub-microscopic backgrounds and sequences of chemical processes. In order to understand chemistry, students have to grasp the concepts of models and their associated resources from the sub-microscopic level and then visualise the processes for themselves. It is the task of teachers to help their students to gain these skills. But herein lies the problem. Mostly used in chemistry lessons are arranged chemical models, arranged experiments with already written How-to's and explanations and 
predefined media. The chemical technical language and terminology - which seems like a complete new foreign language for students - is also a part of the difficulties the students face. A very helpful instrument to overcome these obstacles is communications media in all their variety.

\section{Considerations for learning theory}

"Knowledge and the transfer of knowledge are integral components of something, which can be regarded as the basic form of social life, namely the cooperation of two people in the examination of objects in their environment with the aid of appropriate tools" (Schnotz, 1996, p. 18, translated into English language)

The independent use of knowledge to develop further knowledge, skills and abilities needs constant repetition and helpful tools like media and - as Schnotz stated - a "basic form of social life". This means not only using media but also the use of everyday ideas and knowledge - as long as they are not incorrect or hinder the subject matter - as well as learning in groups. All this together increases the core competencies which also apply to chemistry lessons: social competence, the ability to communicate and the ability to work with media. If the teacher can cause intrinsic motivation, for example through independent activities by students like experimentation or using familiar digital media, useful knowledge can be increased dramatically as Schnotz states in his article.

When it comes to teaching methods there are different methods available, depending on the lesson's purpose. One method utilizes the technical subject of chemistry itself as a point of view. In this case it must be mentioned that in contrast to the everyday experiences of students, this method needs already existing chemical knowledge. Sometimes difficult, but a very interesting way if one likes history, is using the "genesis orientation" where the lesson is based on the origin of a chemical product or a particular development. Mostly used today is a method that focuses on a given problem which poses a question related to everyday life. To solve this problem or question, students have to suggest ways how they can solve the question by themselves. This method indicates a high level of self-organized learning skills by the students, which sometimes is difficult. Another problem in teaching chemistry this way is that the teachers do not know if the students have enough knowledge of everyday phenomena or enough previous knowledge to articulate a problem or hypothesis for solving the problem. If they do not have enough knowledge, students can only investigate the actual situation and have to acquire knowledge directly with the help of the teacher. If they have enough knowledge, students can develop working hypothesis and review them by using appropriate methods and prove or disprove their hypothesis, or, to say it in other words, use the scientific method. According to Kometz and Legall (Kometz and Legall 1994) every type of problem is associated with an appropriate experiment. If it is an Investigation Problem, the students do not have previous knowledge and need to explore the issues of the given problem, an Exploration Experiment can be used to determine the primary contents. If the students have some knowledge and need to explain the subject matter it can occur that they have an 
Explanation Problem which can be solved by a Deciding Experiment. The Prediction Problem comes up with students having chemical knowledge but who need more details. They can be acquired by using a Visualization Experiment. Figure 1 illustrates a Schema of problem types and their relationships.

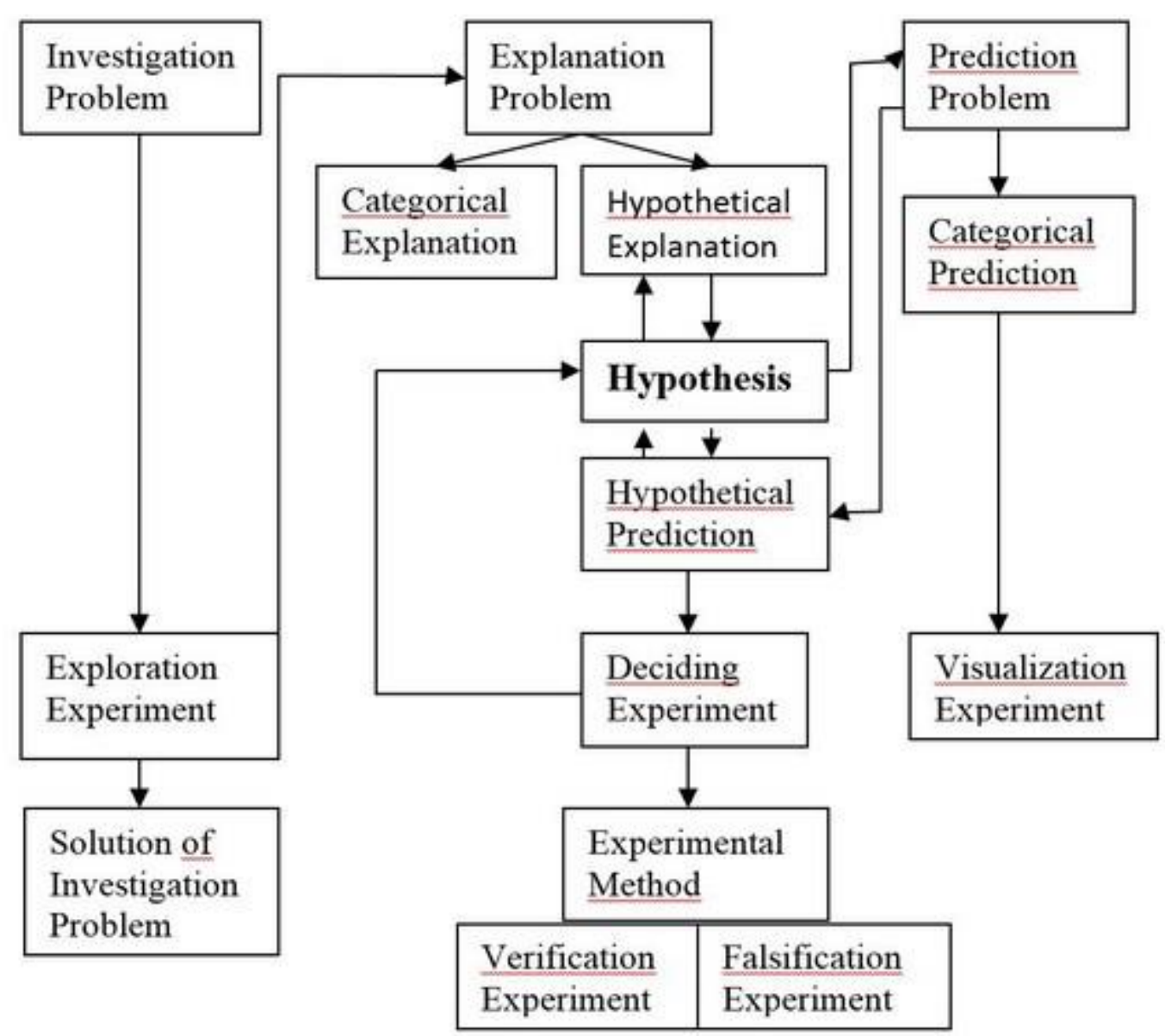

Figure 1: Epistemological Experimental Classification (Urbanger, based on Kometz,1996)

\section{Media in Chemistry lessons}

When it comes to media usable in chemistry lessons, one has to think about the organization of today's society and what the preferences of people in general are. This is necessary due to the fact that students are part of the society and have the same preferences as all others have. Arranged chemical models and arranged experiments with already written down explanations are not enough. The "Medienpädagogischer Forschungsverbund" is annually publishing a study - the JIM Study - in which the authors investigate the role of modern media like Smartphones, Tablet-PC's or Computers among adolescents. The predication of the study is that today's society is really technophilic. The use of Tablet-PCs, PCs and Smartphones is very common among students, even in school - forbidden or not. Therefore, it is necessary to integrate these items in modern school lessons, and - of course - in modern chemistry schooling. 


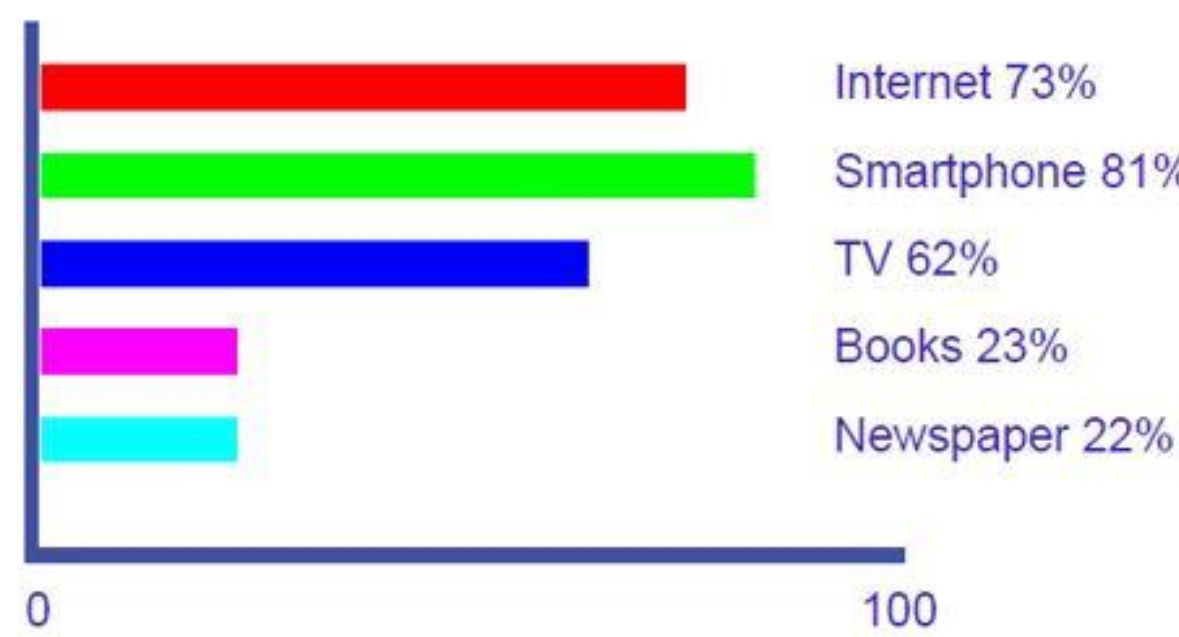

Figure 2: Spare-time activities of students. (Urbanger, based on JIM study 2013)

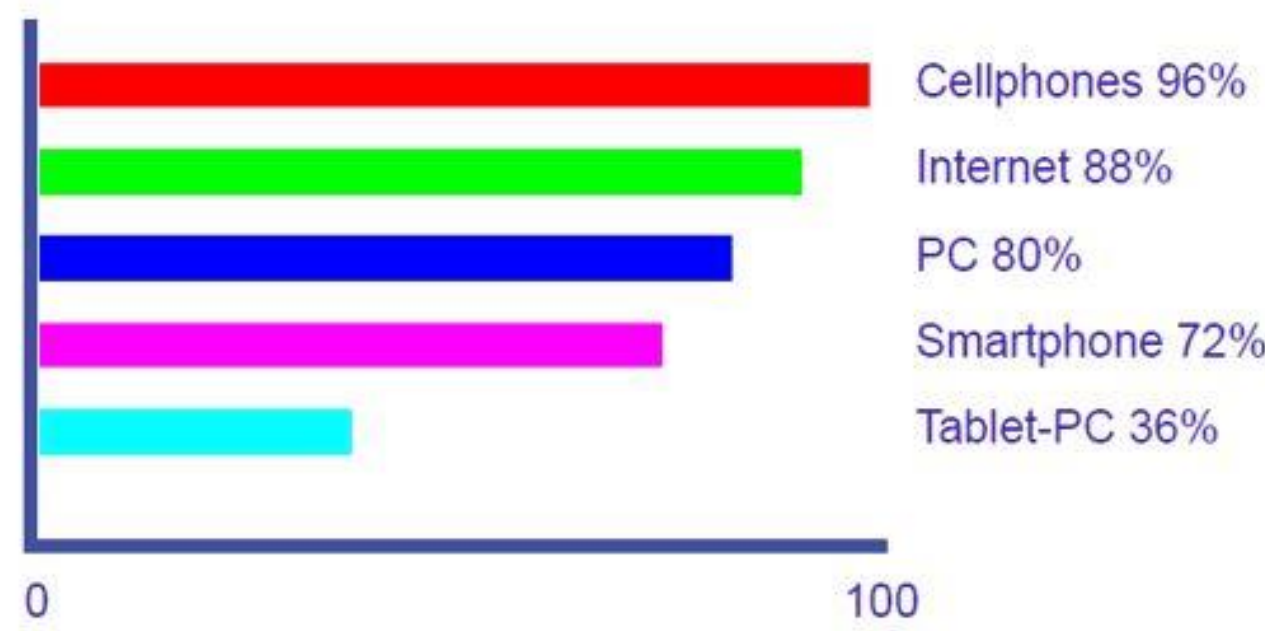

Figure 3: Possession of media devices of students. (Urbanger, based on JIM study 2013)

The use of digital media also implies another meaning of technophile society: The main focus of attention is no longer on printed media or chemical models, but on moving or still pictures and talking, writing and drawing with apps on digital media. This means that models, experiments, chemical structures and explanations on chemical processes must be presented pictorially - either digitally or artistically. Therefore, a co-operation between several subjects like IT for digital visualization and art for creative visual display with chemistry is needed. Chemical knowledge has to be acquired together with competence in media and the ability to visualize chemical processes.

In general, the modern media usable in chemistry lessons have to be combined with other fundamental communications media for describing scientific chemical relationships in school.

"As well as well-tried (and indispensable) methods of teaching, such as the experiment [...] or the blackboard, there are more and more modern methods being used such as the 
interactive whiteboard or the internet, as they can impart essential core knowledge." (Kometz, 2013, p. 364, translated into English language)

Since digital and non-digital media become more varied and are used in multiple combinations, all subjects have to provide media education for the students. Especially in chemistry it is absolutely necessary to let students acquire media competence, since they have to connect the macroscopic, easily visually, aurally and audio-visually tangible level with the submicroscopic level, with no possibility to see atomic or molecular changes. Constant switching between levels is difficult, hence wisely used chemistry media can make the difference between understanding and resignation. Usable media can be in personal forms like language, gestures, movements by the teacher, or in impersonal forms. Impersonal forms can be divided in reality like an original or a preparation, which can be inanimate or alive, it can be a simulation, an illustration or it can be just a symbol. If an experiment, which counts as a simulation, is used, one has to differ between macro experiments (normal sized equipment), semi-micro and micro experiments (very small equipment) that can be executed by students or teachers. If a model is used, one has to differentiate between material models, e.g. molecular diagrams or substances, iconic models, e.g. illustration of atoms, and symbolic models, e.g. written representations.

\section{Mobile Learning}

Learning is the acquisition of knowledge, abilities and skills. Teachers must succeed in appealing to existing knowledge for easier integration of new knowledge. This means, according to the above stated, a teacher has to combine existing abilities in the use of digital media and the specialized knowledge of chemistry. Since many forms of modern media used by students are mobile ones, this combination leads to a new form of learning: Mobile Learning.

Mobile Learning has two meanings: First, one can learn with mobile devices. Second, students can learn, while they enjoy mobility. In the first case, laptops, tablet's and smartphones are used. They can be easily connected to each other (WirelessLAN, Bluetooth), can be easily connected to the internet and the exchange of material suitable for learning can be easily exchanged. Mobile devices have many advantages as learning systems. They appeal to different senses in different ways, there is a versatile form of display and presentation, it is possible to demonstrate learning material in various ways, which can be quickly accessed and edited and - if connected to the internet - there is an extensive collection of material. The students can also use the already known chat-rooms or instant-messenger to discuss topics which are processed in chemistry lessons in school.

The second case is a great chance for students to learn in their own way, not dependent on others or timing. Students have heterogeneous learning requirements and interests. This means that they should have leeway for self-guided work and should choose the locations most conducive for motivation. Learning takes place where the students feel comfortable and can work effectively. If the students can choose their own working environment, they must 
be connected to network communication in order to use programs on their tablet or smartphone or accessing knowledge bases. Summarized, students can consult others online, work in small and linked groups and plan experiments in an alternative way. If Mobile Learning is used, students can acquire a better understanding of submicroscopic processes reviewed with self-planned experiments, visualized with the help of apps and skills from other subjects. Mobile Learning allows obtaining chemical knowledge about a particular topic anywhere, anytime, with anyone in any subject.

\section{Implementation requirements and tentative proposal}

In order to use Mobile Learning, students and schools have some special premises. With respect to school equipment, there has to be a complete technical integration of students PCs, tablet-PCs and smartphones in school, all equipped with access to network communication. With respect to lessons, chemistry teachers must move chemical content into other subjects which presupposes willingness from non-chemistry teachers to participate in this form of learning, since all teachers have to completely change teaching concepts. The didactics of chemistry has to develop collaboration with other didactics for the teachers to handle this task. Preferably, concepts for "subject-mixing" and tryout modules should be evolved that allow the combination of new technology and creativity across involved subjects with chemistry. Therefore it is necessary train teachers in the use of those full-fledged concepts. Chemistry teachers must be trained in building models and render them on computers, evolve illustrations and role-plays, encourage the exchange of ideas, provide real and virtual experiments, tutorials, videos and so on.

The concept is already being tested in a franconian school in Germany (Bavaria). All students and teachers in participating classes are equipped with a tablet-PC and have wireless connection to network communication. The tablet is used as school book, notepad, workbook, research tool, test instrument, film player, presentation device and experimental analysis tool. The school is technically equipped with WirelessLAN access points, efficient severs and software security systems and the chemistry lab is fitted with proper experimental equipment. 


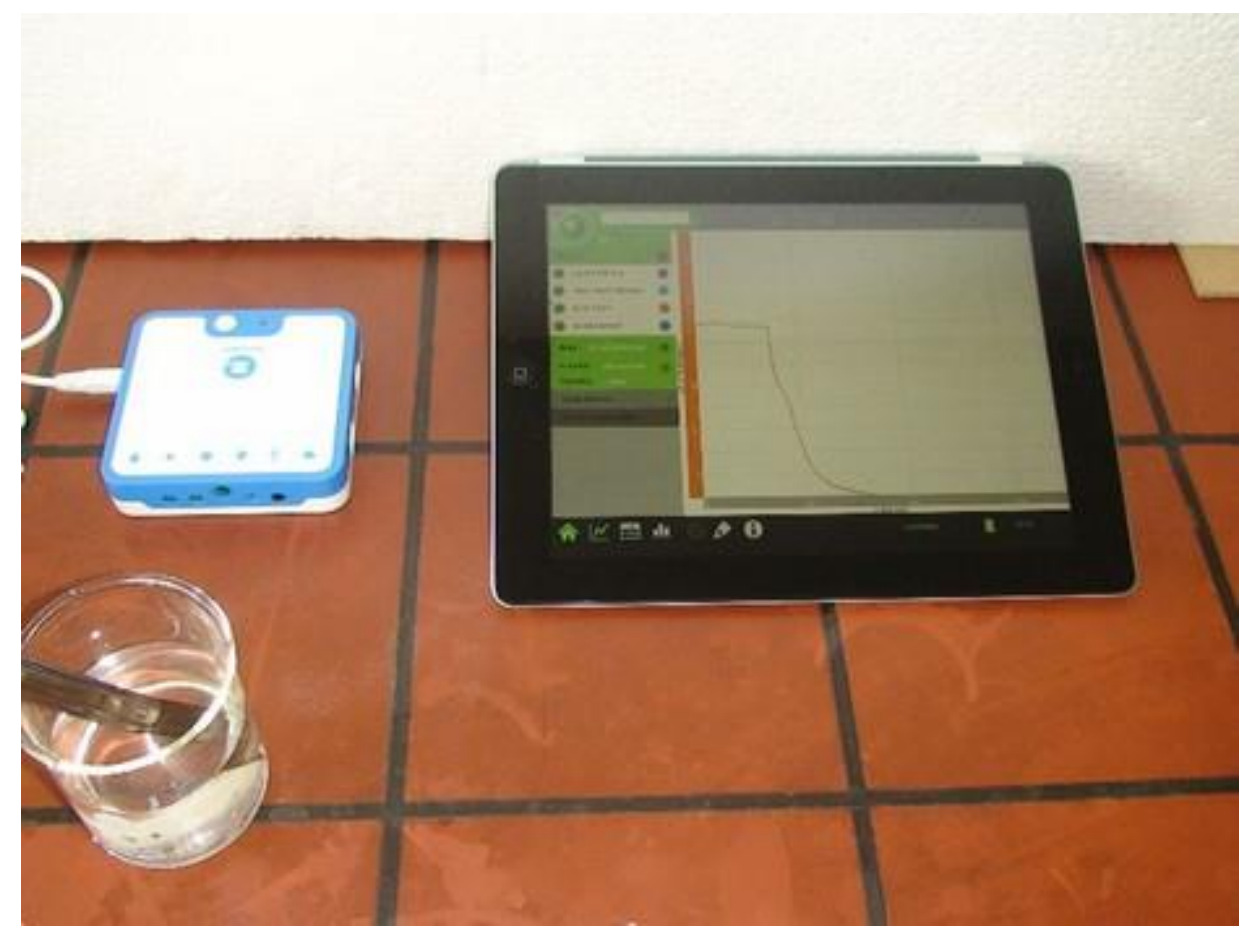

Figure 4: Data analysis tool (C) Urbanger, 2014)

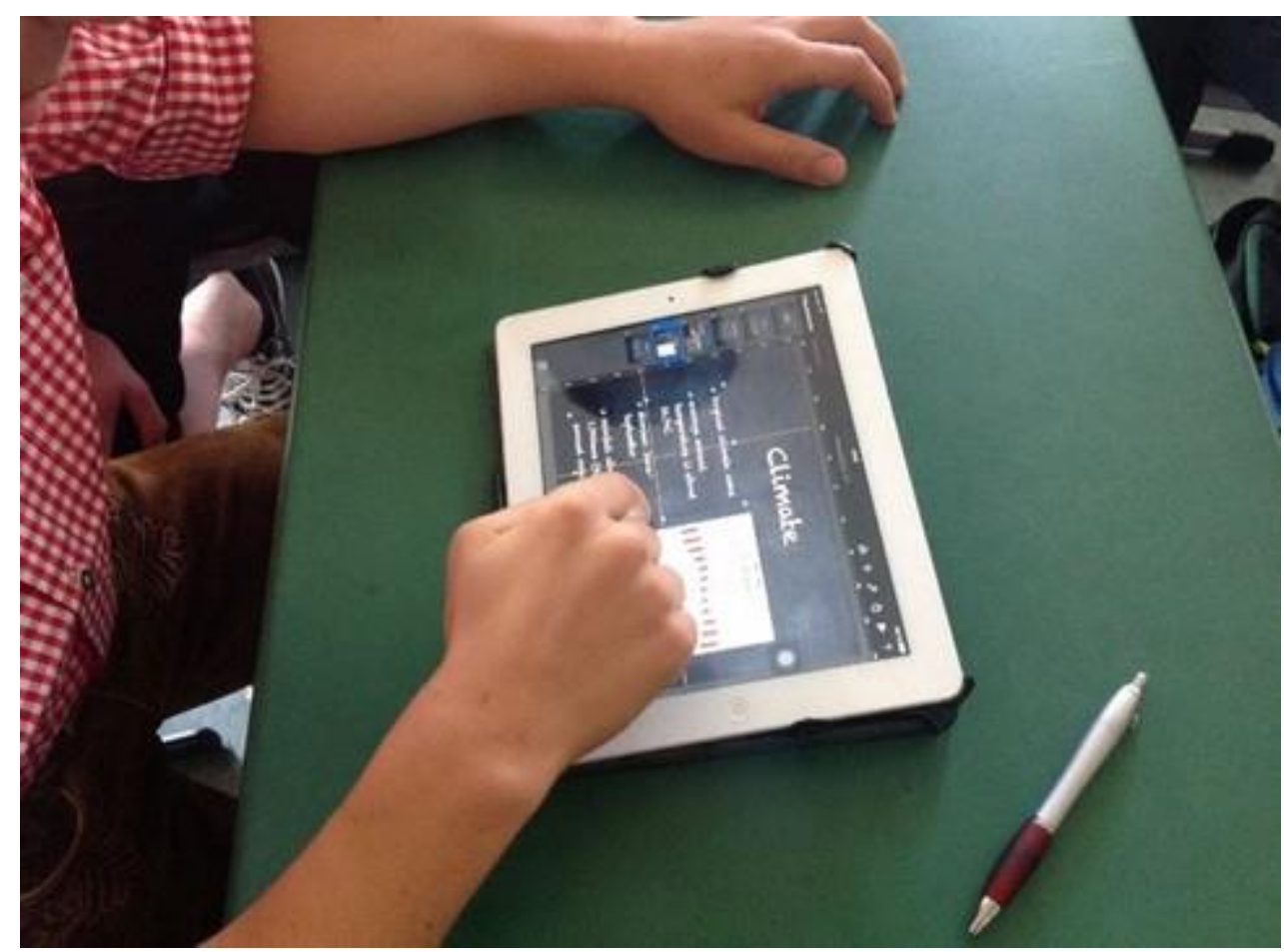

Figure 5: Tablet used by student (C) Urbanger, 2014)

Teachers teaching in the project classes are helpful coaches instead of instructors and are very computer-literate, since there are many in-service trainings in the use of modern technology and software. Students and teachers use apps on their tablet-PCs to make presentations, writings, drawings, calculations, experimental films, they do data analyzing, data logging, modelling of molecules and use an interactive PTE. A school blog has been installed to ensure communication between students and teachers and other students so they 
can receive theoretical and experimental instructions, homework instructions, explanations, internet links and - used as an instant messenger - students can help each other without being together.

If Mobile Learning is used as a concept, the school has to undergo a dramatic change. Not only must teachers be trained in a new way and their lessons have to be adopted to the needs of the project, the technical infrastructure necessary to ensure the concept is also expensive and extensive. But if used consistently, Mobile Learning can provide social skills, media skills, cognitive abilities and scientific knowledge. And, as a welcome side effect, chemistry can be freed from its niche and can be the fundamental science to explain everyday phenomena. 


\section{References}

Barke, H.-D., 2006. Chemiedidaktik: Diagnose und Korrektur von Schülervorstellungen. Heidelberg: Springer Verlag.

Barke, H.-D., 2011. Chemiedidaktik kompakt. Heidelberg: Springer Verlag.

Cole, R., Todd, J., 2003. Effects of Web-Based Multimedia Homework with Immediate Rich Feedback on Student Learning in General Chemistry. Journal of Chemical Education, 8o(11), pp.1338-1343.

Hadenfeldt, J., Parchamnn, I. u.a., 2013. Using Ordered Multiple-Choice Items To Assess Students' Understanding of the Structure and Composition of Matter. Journal of Chemical Education, 9o(12), pp.1602-1608.

Feierabend, S., Karg, U., Rathgeb, T., Behrens, P., 2013.: Medienpädagogischer Forschungsverbund Südwest: JIM 2013. Stuttgart. www.mpfs.de

Kerres, M., 2012. Mediendidaktik. Konzeption und Entwicklung mediengestützter Lernangebote. München: Oldenbourg Verlag.

Kometz, A., 2013. Medienbildung in der Chemiedidaktik. In: M. Pirner, ed. 2013. Medienbildung in schulischen Kontexten. München: kopaed. pp.363-384

Kometz, A., 1996. Zum Einsatz unterstützender Umterrichtsmedien bei Nutzung der Küvettentechnik in Kombination mit Halbmikrotechnik-Gerätesystemen im Chemieunterricht. Frankfurt / M: Peter Lang.

Kometz, A. and W. D. Legall, 1994. Die Küvettentechnik - Überlegungen zum methodischdidaktischen Einsatz im Chemieunterricht In: H. Behrend, ed. 1994. Zur Didaktik der Physik und Chemie. Alsbach / Bergstraße: Leuchtturm-Verlag. pp.229-231.

Kulik, C.-L. and Kulik, J., 1991. Effectiveness of computer-basedinstruction: An update analysis. Computers in Human Behavior, 7(1991), pp. 75-94.

Schnotz, W., 1996. Psychologische Aspekte des Wissenserwerbs und der Wissensveränderung. In: Duit, R. / von Rhöneck, C., ed. 1996: Lernen in den Naturwissenschaften. Kiel: IPN LeibnizInstitut für die Pädagogik der Naturwissenschaften an der Universität Kiel

Stumpf, K., 1979. Das Lernen mit Medien. Der Chemieunterricht, 10(1), pp. 6-24.

Stumpf, K., 1980. Die Projektion von Experimenten im Chemieunterricht. Der Chemieunterricht, 11(1), pp. 5-96. 